\title{
When Dance is Imagined In Cinema: Disclosure in Dance Practice
}

\author{
Marisa Zanotti
}

m

n this paper I explore scenes from two dance worlds on screen and explore how cinematic and narrative strategies are used that, I would propose, ask us to question the conventions of both cinema and dance, as well as to look again at the "reality" of the world around us. One is a "fiction" about a dance company creating a performance from Bizet's opera, Carmen, in Carlos Saura's 1983 work Carmen;and the other, also released in 1983, is Chantal Akerman's documentary "Un Jour Pina a Demandé," about spending five weeks with Pina Bausch's company.

These films may seem poles apart. Saura's is on the surface a mainstream dancedrama, full of virtuoso camera work and technical polish, which explores Bizet's Carmen using familiar dance narrative tropes: youth over experience, and a female heroine being absorbed into a male vision, punished for her sexuality and ultimately sacrificed. Akerman's typically subjective poetic documentary couldn't be more different aesthetically, replete with long takes, as well as sequences that privilege the moments in-between performances as much as the performances themselves.

What strikes me about these two very different works is that they share scenes of dancers looking in mirrors. Initially this linking theme might appear a conventional strategy, as many films with dance as their subject have such scenes. Through exploring the image of the dancer looking in a mirror, either in rehearsal or in the dressing room, this paper will suggest that these works highlight engagements with the real world as being a product of both Baudrillard's notion of the imaginary and also aspects of what he refers to as the process of symbolic exchange.

For many dance artists and academics active in the twenty-first century, it was not dance in theatre but dance on screen (which, by the late twentieth century, was not always simply a filmed stage work) that constituted the first experience of dance. With this came a notion of not just an audience's perspective on dance, but rather what dance might feel like and its expressive potential. Perhaps more strongly the dance viewer also received messages on how to "be a dancer," to live the life of "a dancer"; or, as D'Lugo suggests in a broader argument about Saura's work, that this (dance) identity"is itself the result of a willed submission to a cluster of artistic and social mythologies" (193).' In Baudrillard's terms, this points to a state where the world is produced by the imaginary, which is "the perspective of the human self, its self identifications through images and objects and its capacity to represent — producing the 'illusion' of the real" world (Pawlett 59). ${ }^{2}$ This becomes particularly interesting when considering dance on screen and its capacity to explore and expand not just perceptions of dance or indeed its cinematic potential, but also perhaps how we consider the practice of dance.

In the twenty-first century, mainstream dance narratives on screen often have messages that depict the dance world offering redemption from a future of crime or poverty (Honey), 
or as a safe haven from racial and class divisions (Save the Last Dance). However, there are also the films of the late 1970s like All That Jazz, The Turning Point,or Argento's classic horror Suspiria, which suggest a different kind of dance world: one of self-sacrifice, discipline, loneliness, manipulation of women by male mentors, and drama or/and death as a kind of punishment/destiny for becoming part of this world. Carmen draws on the conventions of the films of the 1970s; it could be said that these films, like Carmen, echo The Red Shoes, although this paper will not enter into a discussion of the influence of The Red Shoes, as much has been written about Powell and Pressburger's film. Un Jour Pina a Demandé offers an insight into the work of Wuppertal Dance Theatre through a documentary on the work of Pina Bausch that has footage of rehearsal, performance, backstage scenes and interviews with both Bausch and Akerman. Here there is no linear narrative thread created and no attempt to cast the work in line with objectivity, or indeed what might be recognized as documentary realism.

In choosing to discuss Carmen I am revisiting a work that excited me when I first saw it in 1983 as a young dancer. Carmen won ten international awards and six nominations, including the Oscar nomination for best foreign film. Twenty-seven years later I am still as excited by how intriguing and provocative it remains today. I would suggest that it is worth examining some of the subversive strategies at work that may on first viewing not be immediately visible, especially in a filmic space where rehearsal, performance and reality become indistinguishable amongst a company of dancers.

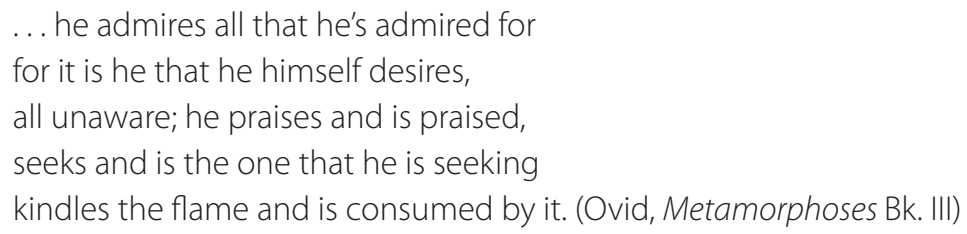

The importance of the mirror in Carmen, and thus its semiotic implications are made evident immediately in the opening of the film. D'Lugo, in his book on Saura, The Films of Carlos Saura: The Practice of Seeing, gives us a detailed analysis of this, and of what he terms the figure of performance (193) as a key theme for discussion. In this book he offers a comprehensive analysis of Saura's Flamenco Trilogy and of the role of the mirror in Carmen. In the filma series of narrative/visual strategies are used through the theme of the mirror and the gaze by way of a contemplation of the image of self and of other dancers. The film foregrounds narcissism and the mirror, and explores the process of looking as an operation that unifies fictional and non-fictional worlds in a state of performance. As the narrative develops, the spectator enters into the world of a play within a play (itself a form of narcissism as the work of art reflects upon itself), with themes of the creation of identities in dance and Spanish culture.

In this context, the question might also be asked, at which point does the dancing body become fictionalized; in dance are we ever really in a fictional body space? The scope of this paper does not permit me to explore all that this question implies but I will begin to consider it as a theme.

Being a dancer is often a process of looking, being looked at by other dancers, and imagining being looked at. Sometimes in the studio the dancer is performing an imagined performance for an imagined spectator. If using a mirror, the dancer might glimpse herself 
performing an imagined performance for an imagined spectator. This addition of another layer of spectatorship is of significance. The sequence from Carmen described below is played in front of mirrors and is intermittently watched by other dancers in the company as they too rehearse.

The character Cristina is pitted against the younger Carmen. Cristina asks to help Carmen demonstrate how to approach a choreographic sequence of elaborate gesture, watching herself in the mirror as she does so. The scene can be read in relation to another familiar trope, exemplified by Antonio the choreographer passing over an older female dancer for a younger woman. ${ }^{3}$ However, what is more interesting in this short scene is the spectator seeing a version of the process of repetition, in this case a reflection on a reflection, a process that is so much part of classical dance practice. There is a depth of understanding here of both dance technique and dance pedagogy. ${ }^{4}$ This scene deals with issues of narcissism, especially when we see Carmen (the character's name) learning that being Carmen (the character in the dance drama of Carmen) is an act that unites mind and body, desire and will. Although Carmen as a character is a fiction, the body of Carmen as Carmen is a reality lived by the dancer. I would in addition suggest that there is a connection for the dancer between the experience of moving accompanied by the simultaneous act of seeing, and being seen in a performance that is both in the present and in the future, an imagined performance.

This is not a separation from the self, but perhaps what the viewer is seeing here is the act of the fictional character Carmen becoming not just Cristina (and there is a hint of that) but also an awareness that she has won out against Cristina. Perhaps it can be suggested that she is becoming "the dancer in the mirror": she is entering a "mirror world" with all the possibilities that this might offer. A mirror world in this context might be defined as a space, which allows the dancer/choreographer to enter into a world, and a process of imagined (and Imaginary) performance. In the mirror world Carmen sees herself in relation to her value in terms of youth and beauty and in her potential as Antonio'sCarmen. However here we might return to Baudrillard who, in "Revenge of The Mirror People" says: "objects, children, the dead, images, women, everything which serves to provide a passive reflection in a world based in identity is ready to go on the counter offensive" (149). ${ }^{5}$ Carmen is no passive ingénue, and whilst the action in the film appears to superficially mirror the Opera's narrative, Antonio tries to create his Carmen and possess herin both the mirror world of the dance he is creating and in the world outside that. She is a modern young woman driven by her own needs and desires. She exists independently of his artistic vision.

Where the film can be read as truly subversive, however, is in showing us that it is Antonio who is in crisis: he is quite literally out of step, a victim of his striving for an authentic, essential truth in a world where there can only be what is produced through representation. This desire is both in relation to his recasting of Bizet's opera and the need to create an ideal, a "real," culturally authentic Carmen. Antonio's vision is of a Carmen that returns the story to its Spanish (as opposed to French) roots. Marshall Leicester, Jr. develops very interesting arguments in relation to Saura's exploration of authenticity in Carmen (something that Antonio Gades was also deeply concerned with in his work with his own company). I will not attempt a full exploration of this argument in this paper but a key point would be that Leicester, Jr. highlights that Flamenco is a recent construction. The dance drama envisioned by the character Antonio is both too close to the clichés of Bizet's opera 
and is also a new form that integrates episodic structure and flamenco, "itself the product of a world where tradition itself is always under construction always being extended to cover and to justify new needs and desires" (256). This would suggest another example of the imaginary attempting to recapture the real. D'Lugo further analyzes the role of the mirror: for example in a scene alone in his studio that not only shows Antonio engaged in a narcissistic display but in the aspect of dance that is critical, contemplative, where thought is visible in the body. On the surface Antonio is choreographing sequences or assessing himself as a dancer, however implicitly in this process of dancing he is also a man struggling to define himself through his body within a culture that is itself being questioned and redefined. I would also add that Antonio's crisis is connected with his performance of another series of roles coming out of the myths of a (screen)dance culture: impresario, jealous lover and aging dancer.

This paper has explored themes of performance through Saura's film Carmen, one of which themes seems to be asking: when does the dancer enter the world of the performance; or rather, when does she leave it? In Un Jour Pina a Demandé (referred to henceforth as Un Jour...) Akerman explores a similar question through images of mirror worlds and in showing rituals around performance and rehearsal. In Un Jour... the still camera in the dressing room shows us what appears to be a familiar image: dancers in the dressing room or in backstage activity, smoking, putting on makeup, sitting around. Here there is sense that, at moments, the dancers, whilst allowing Akerman into their world, do so through a sense of the performance of that world; and that Akerman herself, in her creation of the work, is also engaged in a form of performance.

What Akerman's formal choices create is the possibility to reconsider the significance of these rituals as we move between dressing room/rehearsal and performance. After a while these worlds and these times lead us to explore a space of multiple exchanges. When a dancer sings a folk song to herself in the mirror, is she rehearsing what will happen later in some future Bausch work? We see a couple smoking together; this image gathers momentum when later they perform a disturbing smoking scene. These images reflect one another in different ways in our memory. One remarkable sequence is a montage of dancers applying make-up before and during a show while looking in mirrors: they are powdering their faces, the framing rendering the actions choreographic, the rhythm echoing the rhythm of small gestures in sequences on stage. Akerman playfully draws our attention to the relationship between this ritual of preparation for going on stage, with the rituals of gestures shown on stage.

The film is particularly poignant when she shows us the dancers in quiet moments. We might recognize them from our knowledge of the company on stage, but in comparison to how we see them in a state of performance, when they are driven, physical and vocal, here they appear almost ghostly. The traces of themselves in Bausch's dance works are evident only in what they are wearing; otherwise they seem light, insubstantial. They inhabit in Akerman's world another kind of fiction that of the dressing room versus the "reality" of their personae on stage. Akerman suggests a netherworld that dancers move through; the images hint at them being ghostly figures: looking in the mirror, are they checking they are still present, and if they are, in which world - that of the performance or the real world? Just as in the examples cited previously with respect to Carmen,the space of the mirror again becomes a space for contemplation, both in the repetition of a ritual of preparation and 
as space for gathering the self together again through the narcissistic rituals of grooming. Here the boundaries between fiction and documentary are blurred through Akerman's poetic vision. As in Carmen, looking in the mirror becomes an exchange that takes the dancer and the spectator into another kind of world.

In Akerman's documentary we are not sure (because we are not told) which show we are looking at over the five weeks Akerman spends with the company. ${ }^{6}$ Sometimes we seem to be watching the dancers in a series of altered states, in performance, in rehearsal and in the dressing room. However, through the filmic space she asks the viewer to question fixed ideas about the separation between on and off stage. Throughout the documentary Akerman does not privilege any event as being more interesting or significant than any other. As noted previously it is not unusual for backstage to be a fascinating figure in a film work about dance, but in Un Jour..., where we might expect some kind of revelation that this is where the drama really is, we are instead shown that not too much "happens." Butler quotes from Halbreich and Jenkins in Foster: "hers is a cinema of waiting, of resolutions deferred."When we watch Bausch's dancers in the dressing rooms they appear on the surface to be doing very little. However it becomes clear that we are glimpsing them during not just one performance but also one of a series of performances. Akerman is suggesting something about Bausch's work, an investment by the dancers, and in fact herself, in this process. She immerses the viewer in this world and we are witness to her experience.

It is typical of Akerman that she is interested in mundane activity arising from moments in-between events, and that these non-spaces become events in themselves where time collapses. Here her interests chime with Bausch, for whom duration is an important feature of work. Akerman looks at the work of performance as part of a process, not just one final event. She creates duration where the time of rehearsal, of dressing room and stage overlap. This echoes what we might call "Bausch-time," for Bausch often articulates time in her works as a layering of fictions and memories of childhood, family, adulthood, place, and social and performance rituals.

In this paper I have argued that the cinematic visions of Saura and Akerman invite us to reconsider practice and performance, authenticity and fiction in the context of dance as acts of symbolic exchange. Akerman makes little difference between documentary and fiction, forcing us to question through her radical choices the way in which cinematic conventions create and obscure meaning; this subsequently creates a new lens through which to view familiar scenarios. In Carmen,too, we find radical strategies, perhaps most of all in Saura's treatment of death, wherethe division between the world of the mirror and the world on the other side is removed. Deaths and murders are performed but we are never really sure whether anyone dies or indeed whether Antonio is imagining events. Therefore not only do we have a work that destabilizes us constantly as viewers through shifts of time and space, but also a work where death is rendered as not final.

The subversive potential of performance in Carmen is in turn amplified when that performance is also a performance of death. This resonates with Baudrillard, for whom the separation of life and death is the basis of the power structures and controls produced through binary thinking; and for whom economic/semiotic systems are built on the notion of fixed categories. Performance in this context can also be read in relation to Pawlett's definition of symbolic exchange, being seen in acts which are challenges to these closed systems (48). Or as Baudrillard suggests in The Perfect Crime: "Now the image can no longer 
imagine the real because it is the real" (4). Both Carmen and Un Jour. . . seem to deal in exploring notions of binaries, pointing us towards ideas of performance as a dual form. When Saura and Akerman ask a question in cinema about where dance performance begins and ends, they raise the possibility that dance performance might be both the cut and the suture for a world where Reality is a product of the process of the Imaginary. In these films, dance on screen affords a medium through which complex issues surrounding dance and dancers, performing and performance can be addressed.

\section{Notes}

1. D'Lugo, Marvin. The Films of Carlos Saura: The Practice of Seeing. Princeton: Princeton University Press, 1991. Print.

2. Pawlett, William. Jean Baudrillard. London: Routledge 2007. Print.

3. In the stage version of Gades' Carmen it was Cristina Hoya who played Carmen (muse paper)

4. See Mark Franko on transference in dance pedagogy in: Of the Presence of the Body: Essays on dance and performance theory. Ed. André Lepecki. Middletown: Wesleyan University Press, 2004. 113-123. Print.

5. Baudrillard, Jean. The Perfect Crime. London: Verso, 1996. Print.

6. The final sequences of the work are interviews with both Bausch and Akerman; we find out that the company was performing Bandonen, although there is footage from Nelken in rehearsal and performance filmed while the company was touring, presumably in the five-week period. 